\title{
The co-effect of Sulfamaxone and Zinic on the common soil microbial properties ${ }^{1}$
}

\author{
Liu Aiju ${ }^{1}$, Li Menghong ${ }^{1}$, Wang Honghai ${ }^{2}$ \\ I'School of Recourse and Environmental Engineering, Shandong University of Technology, Zibo 255049, \\ China) \\ ${ }^{2}$ (Zibo entry-exit inspection and quarantine bureau, 63 Liuquan Road, Zibo 255033, China)
}

\begin{abstract}
Antibiotics and heavy metals are often co-occurrence in soils as the wide application of animal feces/manures in agricultural production. To evaluate the interactive effects of antibiotics and heavy metals on soil microbial ecology, the present study investigated the effects of sulfomethoxazole singly or in combined $\mathrm{Zn}$ on soil microbial properties. Results showed that the impact of SMX was some mitigated on soil microbial biomass when Zn was co-added in each soil treatments. However, SMX could seriously inhibit activities of Dehydrogenase and Urease, and then soil nitrification; moreover, this inhibition would be more serious with the co-addition of Zn. These results indicated that combined contamination of SMX and Zn could cause a more serious impact on soil microbial function that on soil microbial biomass
\end{abstract}

Keywords: Zn, sulfomethoxazole, soil microbial biomass, soil enzymes, soil function

\section{Introduction}

Antibiotics and heavy metal are often detected to coexist in soil and organic fertilizer samples. Interactive effect of antibiotics and heavy metal is pronounced on soil microbes [1]. Many studies showed that interactive effect of antibiotics and heavy metals was potentially hazardous to bacteria and other organisms in the environment. Kong et al. reported the antibiotic (OTC) and $\mathrm{Cu}$ had significantly negative effects on soil microbial community function, particularly when both pollutants presented in the environment [1]. Gao et al. reported that the coexistence of antibiotic (OTC) and $\mathrm{Pb}$ can stimulate or suppress the enzymatic activities and microbial number depending on the type of chemical type and incubation time [2].

Sulfomethoxazole (SMX) is one of the more common sulfonamides used for the swine industry. Several studies high-lighted the adverse effects of sulfonamides on soil microbial biomass, structural composition and enzyme activities [3,4]. But this is not the case for SMX. For example, there was no apparent effect on the structure of the soil microbial community and on the mineralization rate of glucose even if the addition of SMX to soil was up to $100 \mu \mathrm{g} \mathrm{g}^{-1}$ [5], although significant effects on soil respiration were reported for SMX application rates of $10 \mu \mathrm{g} \mathrm{g}^{-1}$ soil [6]. On the other hand, the simultaneous addition of three sulfonamides to soil, including SMX, had clear effects on the function and structure of the resident microbial communities even if it was not possible to ascertain the influence of each single antibiotic on soil microbiota [7]. There was little research on co- contamination of SMX and heavy metals.

The aim of this study was to investigate the interactive effects of SMX and Zinc on soil microbial biomass, enzyme activities and nitrification in lab. We hypothesized that SMX in combination with Zinc might reduce or improve its effects on soil microbial activities and then affect the soil ecological function. To this end, we investigated the effects of SMX singly or in combination with Zinc on microbial communities, potential nitrification and selected enzyme activities. It will be very meaningful to assess the risk of sulfonamides on soil microbial ecology.

\subsection{Soil sampling, preparation, and properties}

\section{Meterials and Methods}

The soil was collected from an agricultural field of Zibo, China. Soil was sampled from the plowed topsoil (0-15 cm deep). After the removal of large pieces of plant materials and soil animals, soil was air-dried to about $20 \%$ of maximum water-holding capacity (MWHC) in laboratory. Then, it was milled with a gavel, passed through a $1 \mathrm{~mm}$ sieve, and stored in a dark location at $4{ }^{\circ} \mathrm{C}$ until use. The soil characteristics were listed in Talbe 1.

\footnotetext{
${ }^{1}$ Corresponding Author:Wang Honghai E-mail: aijvliu@ 163.com, Address: Zibo entry-exit inspection and quarantine bureau, 63 Liuquan Road, Zibo 255033, China
} 
Table 1. The selected physico-chemical properties of the soils,

\begin{tabular}{|c|c|c|c|c|c|}
\hline $\mathrm{pH}$ & $\begin{array}{c}\mathrm{OC} \\
\left(\mathrm{g} \cdot \mathrm{kg}^{-1}\right)\end{array}$ & $\begin{array}{c}\text { CEC } \\
\left(\mathrm{cmol}^{\left.-\mathrm{kg}^{-1}\right)}\right. \\
\end{array}$ & $\begin{array}{l}\text { Clay } \\
(\%)\end{array}$ & $\begin{array}{l}\text { Sand } \\
(\%)\end{array}$ & $\begin{array}{l}\text { Silt } \\
(\%)\end{array}$ \\
\hline $7.96(0.11)$ & $16.88(1.49)$ & $35.88(0.14)$ & $45.08(2.34)$ & $38.12(2.05)$ & $14.22(1.83)$ \\
\hline
\end{tabular}

\subsection{Experiment design}

Thirty portions of $300 \mathrm{~g}$ soil were weighed and put into each beaker. Soil moisture was adjusted to $40 \%$ of its MWHC by adding distilled water to the desired weight. The beakers were sealed with plastic film and incubated in the dark at $25 \pm 1^{\circ} \mathrm{C}$ for 7 days.

After 7 days, SMX and $\mathrm{ZnCl} 2$ were applied into the incubated soils. Five treatments of control, S5, $\mathrm{S} 25, \mathrm{~S} 50$, and S100 were spiked with concentrations of $0,5,25,50$, and $100 \mathrm{mg} \mathrm{SMX} \mathrm{kg}{ }^{-1} \mathrm{dry}_{\text {soil, }}$ respectively. For the co-contaminated treatments, $\mathrm{ZnCl}_{2}$ solutions were straightly added to $100 \mathrm{~g}$ soil pretreated with SMX in the rate of $500 \mathrm{mg} \mathrm{kg}^{-1}$ for $\mathrm{Zn}^{2+}$, and then, appropriate pure water was used to adjust the soil moisture to $60 \%$ MWHC. The samples received no SMX and $\mathrm{ZnCl}_{2}$ were selected as control treatment, but an equaled amount of distilled water was added at the same time. Soil moisture was kept constant at $60 \%$ MWHC and was controlled gravimetrically throughout the experiment. The beakers were sealed with plastic film and kept in the dark at $25 \pm 1^{\circ} \mathrm{C}$. The analyses of microbial activities and structure were mostly focused on the sampling dates 14 and 21 days.

\subsection{Microbiological analysis}

Microbial biomass Carbon ( $\mathrm{C}$ mic) was measured using a fumigation and extraction technique [8]. C mic was calculated by subtracting the amount of organic Carbon extracted from the non-fumigated soil from that extracted from the fumigated soil using a conversion coefficient of 0.45 [9].

Enzyme activities were assessed using air-dried soil samples. Dehydrogenase activity (DHA) was determined following the method of Casida et al by the reduction of 2,3,5-triphenyl tetrazolium chloride (TTC) [10]. Urease activity in the soil was determined using a modification of the method proposed by Kandeler and Gerber [11].

Soil potential nitrification rate (PNR) was determined according to the ISO method described by Rusk et al [12]. The extracted $\left(\mathrm{NO}_{3}{ }^{-}+\mathrm{NO}_{2}{ }^{-}\right)-\mathrm{N}$ (referred to hereafter as $\mathrm{NOx}$ ) was analyzed by a colorimetric assay [11]. The production of NOx over the duration of the test was calculated by subtracting the concentration of NOx at day 0 from that at day. The incubation of soil without addition of $\left(\mathrm{NH}_{4}\right)_{2} \mathrm{SO}_{4}$ was used as control.

\subsection{Statistical analyses}

All measurements were made in triplicate and reported as mean values with standard error. Statistical analyses were carried out using SPSS 11.0 (SPSS Inc., USA). For multiple comparisons, it was assumed that the data were from two independent groups. Paired $t$ tests were employed on comparable treatments. Linear regression analysis was used to identify relationships between soil biological and microbial parameters.

\subsection{Effects of SMX and Cu on soil microbial activities}

\section{Results and Discussion}

To study the interaction between SMX and Zn on soil microbial activities, we measured soil microbial carbon and dehydrogenase activity of each soil treatment, respectively. The results are shown in Fig. 1 and 2. As shown in Figure 1, the concentrations of MBC were in the range of 1.04 to $3.85 \mathrm{mg} \mathrm{g}^{-1}$ in treatments with SMX singly; it ranged from 0.004 to $3.73 \mathrm{mg} \mathrm{g}^{-1}$ in treatments with SMX and $\mathrm{Zn}$. That is SMX could pronouncedly decrease soil microbial carbon biomass. And a significant descent trend was found with the increase of SMX spiking level with Zn addition or not, indicating that addition of SMX to soil, either singly or in combination, decreased soil microbial biomass in this study. However, the negative effects on soil microbial biomass were mitigated in soil treatments with SMX and Zn compared to that in SMX single treatments. This does not agree to the post reports that interactive effect of antibiotic and heavy metals was potentially hazardous to bacteria and other organisms, inhibited microbial activities in soil [1,2]. One argues that SMX may chelate heavy metal ions and this chelation could reduce their toxicity [1]. In the current study, the mitigated effect on soil microbial biomass may be caused by this chelation; but antagonistic effect of the both on soil microorganism may be another key factor when they were applied together. 


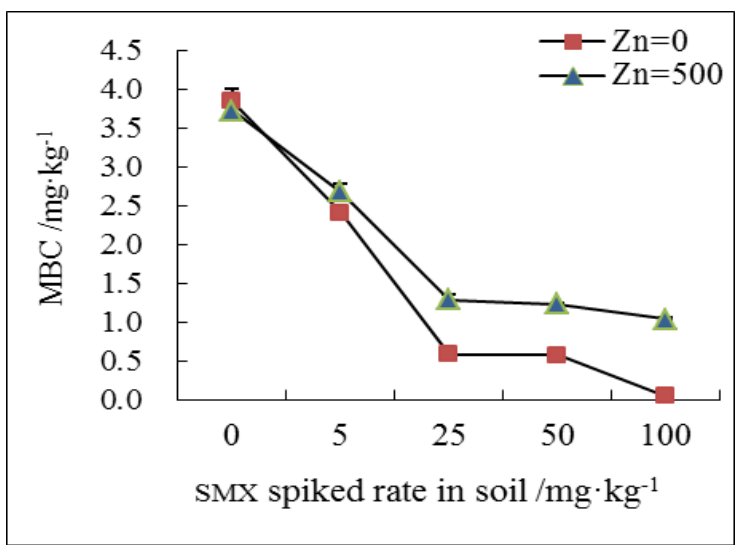

Fig. 1. Effects of SMX and Zn on MBC.

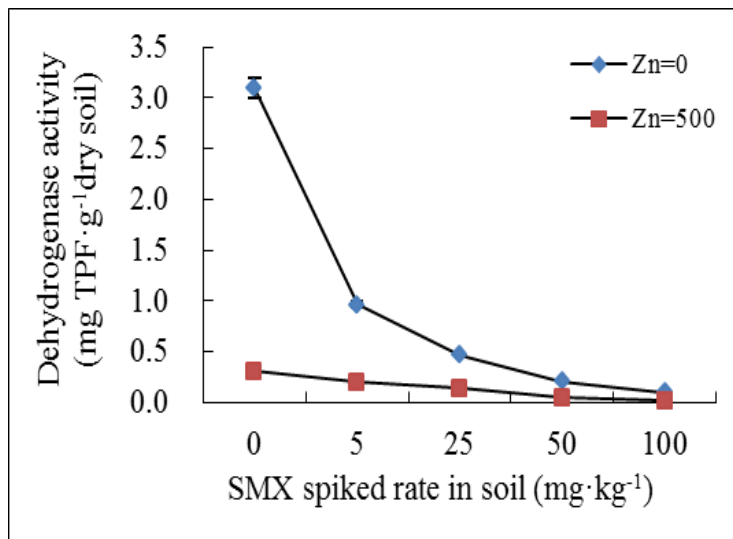

Fig. 2. Effects of SMX and Zn on DHA.

The dehydrogenase (DHA) activity reflects the functionality of a group of intracellular enzymes to oxidize organic compounds, providing a measure of the total oxidative activity of soil microflora. In this sense DHA activity can provide useful information on the stress level faced by soil microbial communities [13]. As shown in Figure 2, DHA was substantially reduced when SMX were present, and DHA inhibition increased with increasing SMX concentration, either singly or in combination. This is similar to the observation by observations by [14]. Moreover, when applied together, the activities of dehydrogenase were more seriously inhibited than that in SMX singly treatments, indicating a synergistic effect of the two pollutants on DHA。

\subsection{Effects of SMX and Zn on soil function}

In order to draw a clearer picture of the interactive effect of SMX and $\mathrm{Zn}$ on soil microbial function, Urease activity and soil potential nitrification were determined in different soils treatments. The results were shown in Fig. 3 and 4.

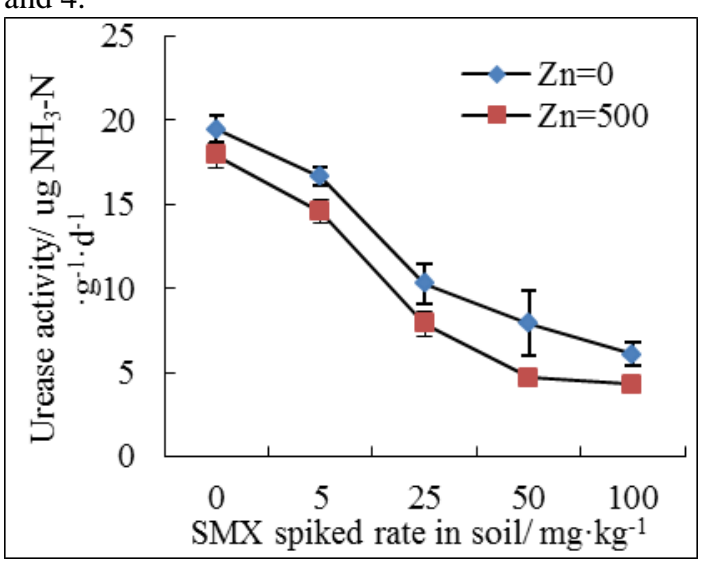

Fig 3. Effects of SMX and Zn on Urease activity .

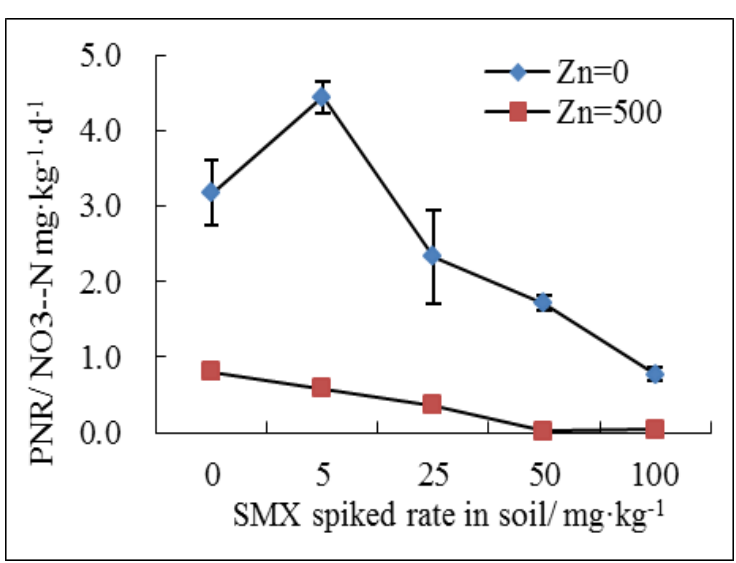

Fig 4. Effects of SMX and Zn on soil nitrification.

As shown in figure 3, soil urease activity was also reduced with increasing SMX spiking level without it singly or in combination; but it was always relatively higher in Zn coexist soil treatments than that in SMX singly addition treatment, which was similar to the effects of SMX and $\mathrm{Zn}$ on soil microbial biomass. The similar effects of SMX(singly or in combination) on UA and soil microbial biomass are in agreement with reports by Klose and Tabatabai [15] who reported a correlation of microbial biomass with UA.

As shown in figure 4, PNR in the control sample was evenly $3.17 \mathrm{NO}_{\mathrm{x}}^{-}-\mathrm{N} \mathrm{mg} \mathrm{kg}^{-1} \mathrm{dm} \mathrm{day}^{-1}$. In $5 \mathrm{mg}$ $\mathrm{kg}^{-1}$ SMX treatments, it was $4.44 \mathrm{NO}_{\mathrm{X}}^{-}-\mathrm{N} \mathrm{mg} \mathrm{kg}^{-1} \mathrm{dm} \mathrm{day}^{-1}$, which was significantly accelerated by the addition of SMX. However, PNR was significantly inhibited in treatments with SMX over $5 \mathrm{mg} \mathrm{kg}^{-1}$. Moreover, the coaddition of SMX and $\mathrm{Zn}$ caused more serious impact on the soil nitrification. It indicated that a synergistic effect of the two pollutants on soil nitrification. This agreed with the results of DHA and Urease activities analysis in this study.

\section{Conclusion}

In this study, SMX could seriously inhibit activities of Dehydrogenase and Urease, and then soil nitrification; moreover, this inhibition would be more serious with the co-addition of $\mathrm{Zn}$. However, the impact of SMX was some mitigated on soil microbial biomass when $\mathrm{Zn}$ was co-added in each soil treatment. These results indicated that combined contamination of SMX and $\mathrm{Zn}$ could cause a more serious impact on soil microbial function that on soil microbial biomass. 


\section{Acknowledgment}

The study was supported by the international visiting project of Young Teachers in universities of Shandong Province, China, and the Foundation of Shandong University of Technology (NO.4072).

\section{REFERENCES}

V. W. Kong, Y. Zhu, B. Fu, P. Marschner, J He. The veterinary antibiotic oxytetracycline and Cu influence functional diversity of the soil microbial community. Environemtal Pollution, 143(3), 2006,129-137.

VI. M. Gao, W. Song, Q. Zhou, X. Ma, X. Chen. Interactive effect of oxytetracycline and lead on soil enzymatic activity and microbial biomass. Environmental Toxicology and Pharmacology, 36(2), 2013,667-674.

VII. L. Aldén Demoling, E. Bååth, G. Greve, M. Wouterse, H. Schmitt. Effects of sulfamethoxazole on soil microbial communities after adding substrate. Soil Biology and Biochemistry, 41, 2009, 840-848.

VIII. U. Hammesfahr, A. Kotzerke, M. Lamshöft, B.-M. Wilke, E. Kandeler, S. hiele-Bruhn, "Effects of sulfadiazine-contaminated fresh and stored manure on a soil microbial community," Eur J Soil Biol, 2011,47: 61-68.

IX. C. Accinelli, A. Barra Caracciolo, P. Grenni. Degradation of the antiviral drug oseltamivir carboxylate in surface water samples. International Journal of Environmental Analysis and Chemistry, 87, 2007,579-587.

X. F. Liu, G. Ying, J. Yang, et al. Dissipation of sulfamethoxazole, trimethoprim and tylosin in a soil under aerobic and anoxic conditions. Environmental Chemistry, 7, 2009, 370-376.

XI. I.R. Gutiérrez, N. Watanabe, T. Harter, B. Glaser, M. Radke. Effect of sulfonamide antibiotics on microbial diversity and activity in a Californian Mollic Haploxeralf. Journal of Soils and Sediments, 10, 2010,537-544.

XII. P. C. Brookes, A. Landman, G. Pruden, D.S. Jenkinson. Microbial biomass and activity in an agricultural soil with different organic matter contents. Soil Biology and Biochemistry, 17, 1985, 611-618.

XIII. J. Wu, R. G. Joergensen, B. Pommerening, R. Chaussod, P.C. Brookes. Measurement of soil microbial biomass C by fumigationExtraction an automated procedure. Soil Biology and Biochemistry, 22, 1990,1167-1169.

XIV. L.E. Casida, D. Klein, T. Santoro. Soil dehydrogenase activity. Soil Science, 98, 1964, 371-376.

XV. E. Kandeler and H. Gerber. Short-term assay of soil urease activity using colorimetric determination of ammonium. Biology and Fertility of Soils, 6, 1988, 68-72.

XVI. J. A. Rusk, R.E. Hamon, D.P. Stevens, M.J. McLaughlin. Adaptation of Soil Biological Nitrification to Heavy Metals. Environmental Science and Technology, 38 (11), 2004,3092-3097.

XVII. A. Oliveira and M.E. Pampulha. Effects of long-term heavy metal contamination on soil microbial characteristics. Journal of Bioscience and Bioengineering, 102(3) 2006,157-161.

XVIII. M. V. Pinna, P. Castaldi, P. Deiana, A. Pusino, G. Garau. Sorption behavior of sulfamethazine on unamended and manure-amended soils and short-term impact on soil microbial community. Ecotoxicology and Environmental Safety, 84, 2012, $234-242$. 